sequence of sexual and asexual phases in the case of Antithamnion spirographidis Schiffner. This alga is a native of the Mediterranean but has also been reported from Plymouth by Westbrook ${ }^{4}$. It appears to grow comparatively well in marine aquaria, and the material used in this experiment came from an aquarium in the Zoology Department of this University. My thanks for it are due to Prof. H. Graham Cannon.

Tetraspores were liberated from two plants at the end of October 1954, and the development of plants from nine of these has been followed. After liberation of a few tetraspores, the parent filaments were quickly removed, as minute fragments are capable of rapid attachment by the production of rhizoids and of subsequent development into new individuals. At the end of the month, nine germlings were moved to individual culture dishes, the transfer causing a temporary slowing down in growth. However, by January 12, 1955, spermatangia were to be seen on four plants and procarps on a fifth. Spermatangia were abundant on two of the four male plants. By February 1 procarps could be seen on the remaining four plants. This development of spermatangia on four plants and procarps on five suggests the existence of sex chromosomes and segregation at meiosis in the tetrasporangium; but on February 1 spermatangia were to be seen on the plant on which procarps were found on January 12 and in addition an immature carposporophyte. By February 18 there were numerous mature carposporophytes on this plant. The occurrence of both male and female reproductive organs on one plant indicates the need of a much more extensive experiment. In addition, a few cells resembling tetrasporangium mother-cells were seen on one of the female plants but never any mature tetrasporangia.

Carpospores of $A$. spirographidis were germinated in October 1952

and the resulting plants kept together in one culture dish. By February 1953, numerous tetrasporangia had developed on them. These plants were not grown under the same conditions as the plants raised from tetraspores and so comparison with the time taken for the development of sexual reproductive organs is of no value.

While the numbers of plants involved in this preliminary work is small, the evidence so far as it goes shows that tetrasporophytes develop from carpospores and sexual plants from tetraspores. This appears to be the first record of the development of plants from both tetraspores and carpospores of the same species to maturity and reproduction. It has also shown that carposporophytes develop in less than eighteen days. The preliminary nature of this work must be emphasized, however.

Kathleen M. Drew

Department of Cryptogamic Botany,

University, Manchester. March 15.

'Lewis, I. F., Bot. Gaz., 53, 236 (1912)

2 Dammann, H., Wiss. Meeresuntersuch., 18, 26 (1930).

s In Hartmann, M., "Die Sexualitat" (Jena, 1943).

4 Westbrook, M. A., J. Bot., 72, 65 (1934).

\section{Juvenility Phenomena associated with Crown Gall}

IN a review of juvenility phenomena, Allsopp ${ }^{1}$ recently emphasized the close apparent connexion between nutrition and the development of juvenile leaf-forms. In this Department the factors affecting regeneration of plants from roots are the subject of a general study ${ }^{2}$, in the course of which juvenile characters have been observed on young root suckers produced by several species. These will be described in detail elsewhere, but it may be of interest to refer to a special case which has occurred.

When adventitious shoots grow from root cuttings of raspberries (Rubus idaeus L.), the earliest leaves are usually of pronounced juvenile form, especially when they grow (a) from thin roots $^{3}$, or $(b)$ from small pieces of root, or (c) from pieces of dying root, or $(d)$ at high temperatures. In shoots which continue to develop, successive leaves become progressively more adult in form, first deeply lobed and later compound (Fig. 1, plant $A$ ). 